\title{
NASA NOISE REDUCTION PROGRAM FOR ADVANCED SUBSONIC TRANSPORTS
}

\author{
David G. Stephens and F. W. Cazier, Jr. \\ NASA Langley Research Center \\ Fluid Mechanics and Acoustics Division \\ Hampton, Virginia 23681, USA
}

\section{INTRODUCTION}

Aircraft noise is an important byproduct of the world's air transportation system. Because of growing public interest and sensitivity to noise, noise reduction technology is becoming increasingly important to the unconstrained growth and utilization of the air transportation system. Unless noise technology keeps pace with public demands, noise restrictions at the international, national and/or local levels may unduly constrain the growth and capacity of the system to serve the public. In recognition of the importance of noise technology to the future of air transportation as well as the viability and competitiveness of the aircraft that operate within the system, NASA, the FAA and the industry have developed noise reduction technology programs having application to virtually all classes of subsonic and supersonic aircraft envisioned to operate far into the 21 st century. The purpose of this paper is to describe the scope and focus of the Advanced Subsonic Technology Noise Reduction program with emphasis on the advanced technologies 1,2 that form the foundation of the program.

\section{BACKGROUND}

Historical Perspective. NASA's responsibility in noise research is to generate advanced noise prediction and noise reduction technologies for use by the Federal Aviation Administration (FAA) as a technical basis for establishing noise standards, and for use by the aeronautical industry to assure the development of products that will meet the standards without undue economic penalties. The information also supports the development of flight operational procedures as well as airport and community planning measures which can be used to further reduce undesirable effects of noise.

NASA's noise research, which dates back to the 1940 's, became a major effort shortly after the introduction of jet transports, when it was recognized that unless large noise reductions were achieved, noise could become a serious public nuisance and an obstacle to the development of an adequate national air transportation system. The effort has been a closely coordinated activity involving the NASA research centers, the FAA, the engine and airframe manufacturers, and a number of university and private research groups. The noise reduction research has been focused on understanding, predicting, and suppressing all of the various noise sources. It has also of necessity included intensive analytical and experimental studies of the noise propagation from the aircraft to the ground, as well as the perceived effects of the noise-and of various noise alleviation measures - on human beings.

Figure 1 gives a history of jet commercial airplane noise levels. Plotted in this Boeing figure is the sideline certification point noise level normalized to $100,000 \mathrm{lb}$ thrust for each airplane/engine configuration at the time of initial service. In early turbojet engines, the high-velocity jet exhaust, mixing with the surrounding air, was the major noise source. In the 1960's, low-bypass-ratio turbofan engines were introduced. The turbofans offered greater propulsive efficiency than the turbojets, and they provided some noise relief as well. With the help of internal mixers, the engine core and fan exhausts were combined, resulting in a lower jet exhaust velocity and therefore a significant reduction in jet exhaust noise.

An even greater reduction in jet exhaust noise was achieved when the higher-bypass-ratio second generation turbofans arrived with the wide-bodied transports. However, with the reduced jet exhaust noise no longer the primary noise source, further improvements required reduction of the fan-generated noise as well as the jet noise. In 1967, NASA initiated an acoustically treated nacelle program, in which engine ducts and inlets were lined with acoustic treatments and flight tested on a Boeing 707 and a Douglas DC-8. Successfully achieving the design goal of reducing noise under the approach path by as much as $15 \mathrm{PNdB}$, the Quiet Nacelle ${ }^{3}$ program proved that 
ground. The objective of this subelement is to achieve a 65 DNL outside the vertiport control area to meet the FAA recommended community noise criterion. A reduction of $6 \mathrm{dBA}$ is the goal for rotor source noise and another $6 \mathrm{dBA}$ through optimized flight procedures. This subelement will investigate a range of rotor concepts that employ tip speed reduction, disk loading reductions, advanced planforms, optimal number of blades and mechanical devices to reduce the rotor noise.

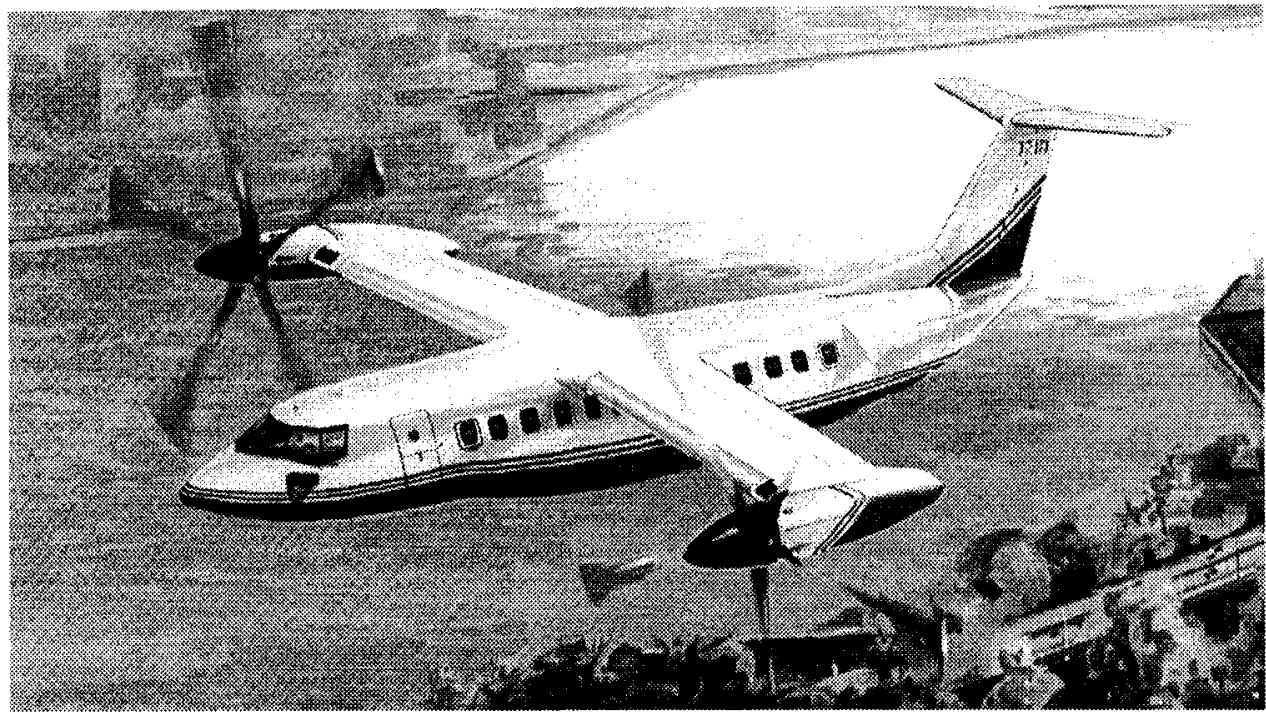

Figure 8. Forty Passenger Civil Tiltrotor-Artist Concept.

The noise reduction concepts of the noise reduction subelement will provide the foundation for the development, analysis and testing of viable proprotor configurations for advanced tiltrotors. However, noise reduction is only one of the constraints on a viable proprotor configuration. In achieving the noise reduction targets, the rotor must not suffer from degradation in performance, loads, aeroelastic stability and vibration. The deliverables of this element are one or more efficient, low noise proprotor concepts validated in model scale and rotor noise reduction validated in a large scale test.

\section{SUMMARY}

The Advanced Subsonics Technology program was initiated in late 1993. The program consists of 10 elements or programs. Acoustics technology is an important factor in most of these programs. The AST Noise Reduction program and the AST Short Haul- Civil Tiltrotor program are discussed in some detail. The objective of these acoustics programs is to provide innovative acoustics technology required by the industry for developing environmentally compatible and economically viable aircraft for the subsonic flight regime. These programs are exploiting advanced technologies such as computational aeroacoustics, active noise control, and advanced propagation and prediction methods.

\section{REFERENCES}

1. Hubbard, Harvey H., ed.: "Aeroacoustics of Flight Vehicles: Theory and Practice-Volume 1: Noise Sources," NASA RP-1258-VOL-1 (1991)

2. Hubbard, Harvey H.: "Aeroacoustics of Flight Vehicles: Theory and Practice-Volume 2: Noise Control," NASA RP-1258-VOL-2 (1991)

3. Anon.: "NASA Acoustically Treated Nacelle Program" NASA SP-220 (1969)

4. Anon.: "Quiet Powered-Lift Propulsion," NASA CP-2077 (1979)

5. Cornwell, W. G.: "Experimental Quiet Engine Program," NASA CR-2519 (1975)

6. German, J.; Fogel, P.; and Wilson, C.: "Design and Evaluation of an Integrated Quiet, Clean General Aviation Turbofan (QCGAT) Engine and Aircraft Propulsion System" NASA CR-165185 (1980)

7. Hager, Roy D.; and Vrabel, Deborah: "Advanced Turboprop Project," NASA SP-495 (1988)

8. Smith, Michael J. T.: Aircraft Noise. Cambridge University Press (1989)

9. Silcox, Richard J.; Lefebvre, Sylvie; Metcalf, Vern L.; Beyer, Todd B.; and Fuller, Chris R.: Evaluation of Piezoceramic Actuators for Control of Aircraft Interior Noise. "Proceedings of the 14th DGLR/AIAA Aeroacoustics Conference," 2, 542-551 (1992) 
Interior Noise Reduction. The goal of the interior noise reduction subelement is to develop and validate weightefficient technology to minimize cabin and cockpit noise in commercial and general aviation aircraft, including advanced civil tiltrotors. Design tools for low noise transmission will be developed, and practical broadband control demonstrated through passive concepts and through active noise control. The objective is to produce technology capable of yielding a $6 \mathrm{~dB}$ overall interior noise reduction by the year 2000 . The application of active structural acoustic control technology is illustrated in figure 7 from a test at the NASA Langley Research Center. A filament wound graphite epoxy composite shell, approximately 5.5 feet in diameter and 11.5 feet long, represents the fuselage of a commuter airplane. An external speaker representing a propeller source is driven at a fixed frequency. The resulting exterior acoustic pressure fluctuations excite the shell and generate the interior pressures indicated in the pressure contours. Piezoelectric actuators, bonded to the skin at two locations shown in the figure by arrowheads are driven by a feedback control system using interior microphones as an input signal. Using just these two actuators, an average and peak SPL reductions of approximately $12 \mathrm{~dB}$ were attained throughout the interior space. ${ }^{9}$

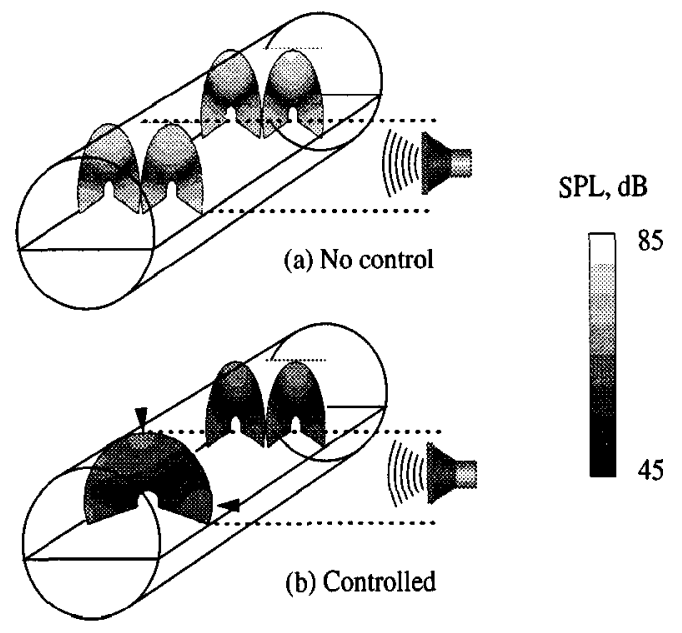

Figure 7. Active Interior Noise Control System.

Community Noise Impact. The goal of the community noise impact subelement is to provide technology to reduce noise impact of aircraft and airport operations through application of new aircraft technologies and operational procedures, through improved noise impact modeling and prediction, and through improved understanding of relationships between human response and aircraft noise exposure variables. The specific goal is to produce a community noise impact minimization model by 1999 which can be used to determine optimal landing approach and takeoff procedures for arbitrary aircraft at any given airport.

\section{SHORT HAUL- (CIVIL TILTROTOR)}

The civil tiltrotor offers a unique opportunity to create a new aircraft market while off loading major airports of a large portion of the short haul traffic. Studies have shown the civil tiltrotor, figure 8 , to be a viable candidate for air traffic congestion relief. Without significant new noise reduction technology, however, it will be impossible to achieve community acceptance that is essential to the establishment of conveniently located vertiports. The Short Haul (Civil Tiltrotor) element of the AST program is an effort to develop the most critical technologies for a civil tiltrotor: noise reduction; cockpit technology; and power for one engine inoperative operation. Two subelements of this program provide the noise reduction technology from which full scale development decisions can be made. These are the noise reduction, and the efficient, low-noise proprotor subelements which are described below .

The noise reduction subelement will identify and analyze concepts and flight procedures that will minimize the noise levels of a tiltrotor aircraft in critical terminal area operations. While the tiltrotor is generally quieter than a helicopter in forward flight it has noise characteristics similar to a helicopter in the terminal area. Two methods are available for the reduction of the noise levels at ground level near the vertiport: (1) the reduction of the source noise from the rotor system, and (2) the use of advanced flight procedures to avoid operating condition of high rotor noise where blade vortex interaction (BVI) noise occurs and the control of flight paths to avoid sensitive areas on the 
treatment in the inlet and exhaust may, through technology development, be replaced by even higher bypass ratio engines, with short nacelles and active acoustic absorption and active noise cancellation at the source.

\section{Existing}

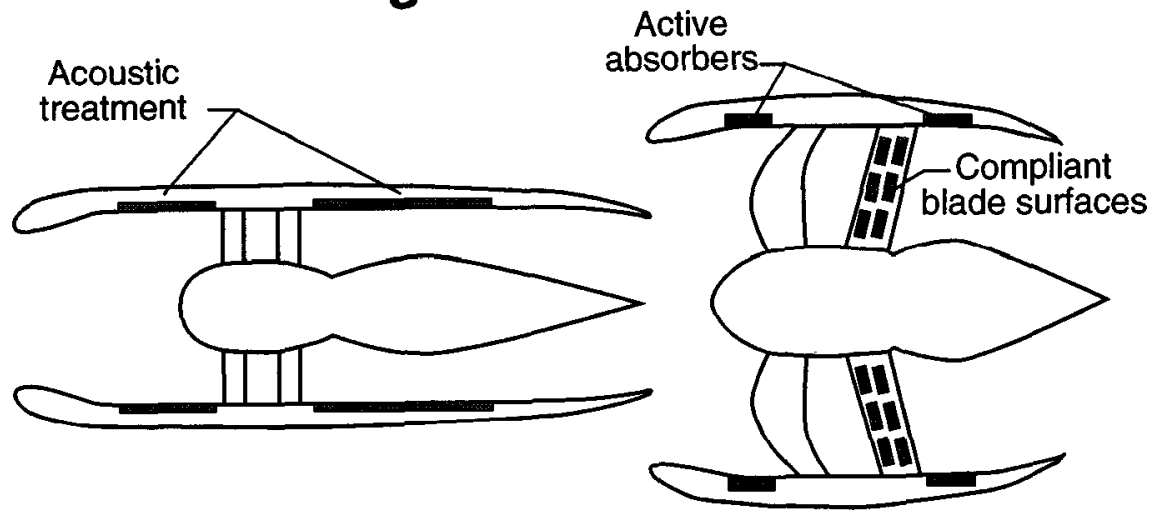

Passive control Technology Active cancellation

Figure 5. Noise Control Treatments.

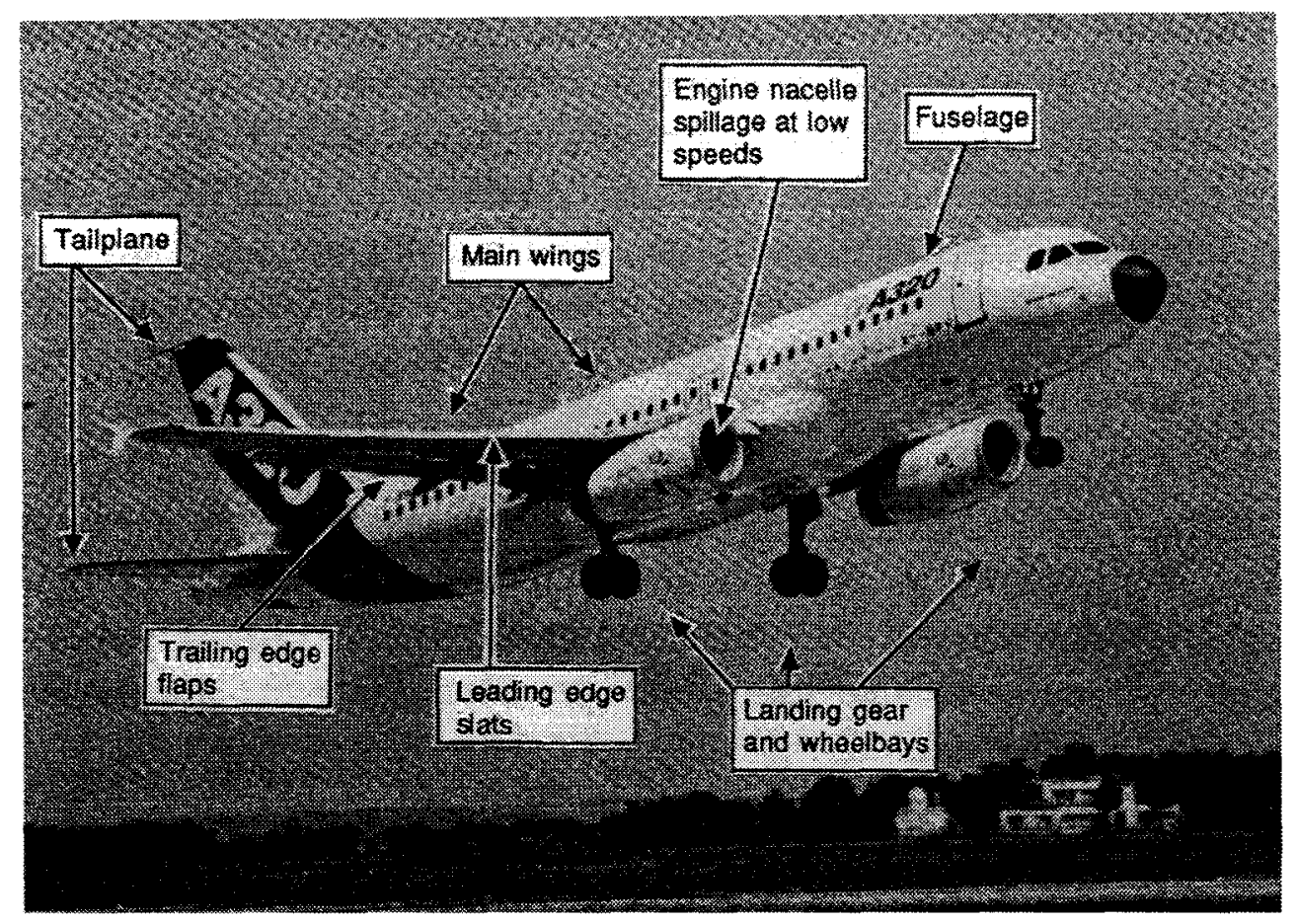

Figure 6. Ainframe Noise Sources.

Acoustic/Aerodynamic Integration and System Evaluation. The objective of the integration and system evaluation subelement is to develop and validate system noise prediction and minimization methods to include engine/pylon/wing installation effects and airframe noise. The emphasis is on the acoustic and aerodynamic integration of turbofan engines with high-lift systems operating under both takeoff/climbout and approach/landing conditions. Figure 6 from chapter 7 of reference 8 illustrates some of the airframe noise sources. Specific goals of this subelement include the capability to reduce airframe noise $4 \mathrm{~dB}$ below current levels, eliminate the noise penalty due to the interaction of the engine and the wing high-lift system while at least maintaining the current level of highlift performance, and identify or eliminate areas of risk when model scale experiments are used to predict the performance of flight hardware under flight conditions. 
Engine Noise Reduction. The objective of the engine noise reduction subelement is to provide technology to reduce engine noise levels $6 \mathrm{~dB}$ relative to 1992 technology by the end of the decade. A near term objective (1996) is to provide technology for reducing jet noise for lower bypass ratio (1.5-6) engines, and the technology for

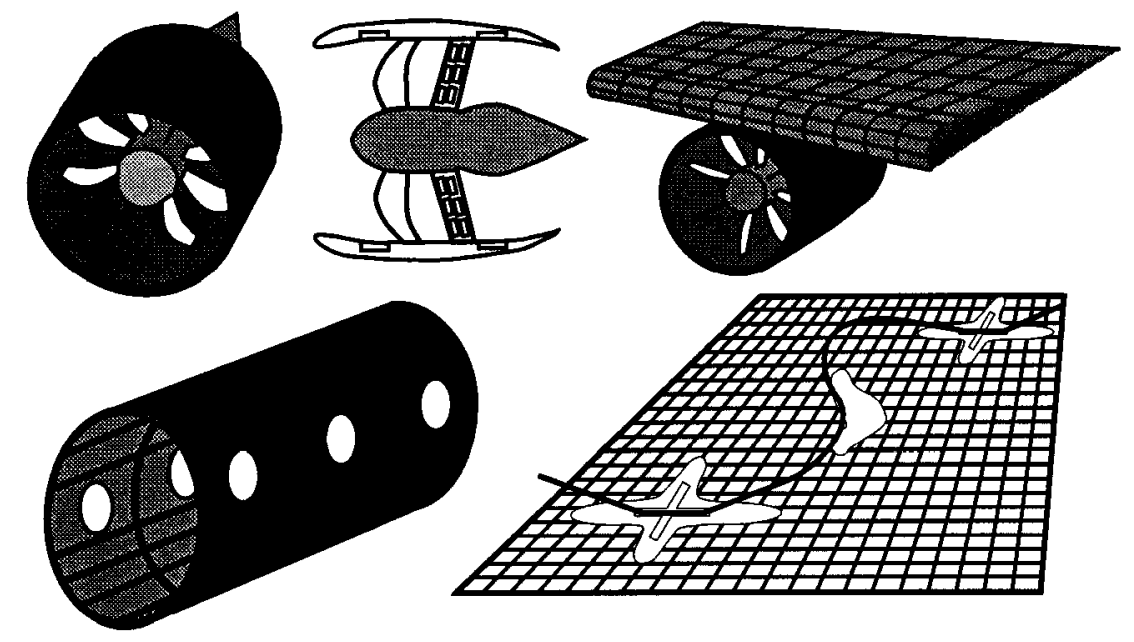

Figure 2. Advanced Subsonic Technology Noise Reduction Program Subelements.

reducing fan noise $3 \mathrm{~dB}$. Advanced noise prediction methods based on fundamental principles are being developed. These codes will be used to understand noise generation mechanisms, and to evaluate noise reduction concepts. These noise reduction concepts will be tested on high fidelity scale model engines. Several engine simulators will be used in the program including the $12 \mathrm{in.,} 17 \mathrm{in}$. and $22 \mathrm{in.} \mathrm{models} \mathrm{of} \mathrm{the} \mathrm{Pratt} \mathrm{and} \mathrm{Whitney} \mathrm{Advanced} \mathrm{Ducted}$ Propulsor, a 22 in. model of the General Electric Universal Propulsion Simulator, and a 22" in. Allison engine model. Figure 3 shows the 17 in. model of the P\&W ADP being tested in the NASA Lewis Research Center $9 \mathrm{ft}$. $\mathrm{x} 15 \mathrm{ft}$. wind tunnel. Figure 4 is a comparison of predicted and measured fan tone noise levels from this test. The predicted values shown are from an integrated prediction code which brings together source noise, propagation within the nacelle, and radiation prediction codes. Predicted unsteady pressure distributions on the engine struts, a key noise source mechanism, and the noise field at the inlet of the engine are also shown.

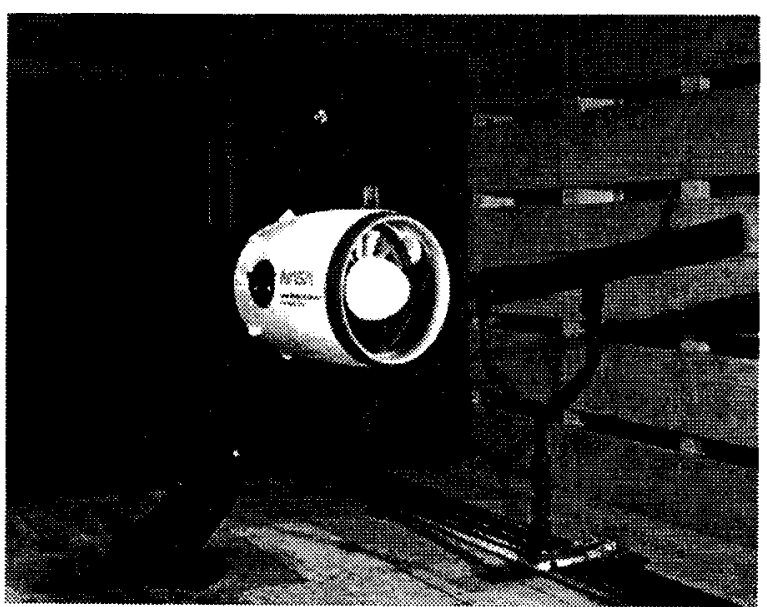

Figure 3. Engine Model in 9'x15' tunnel.

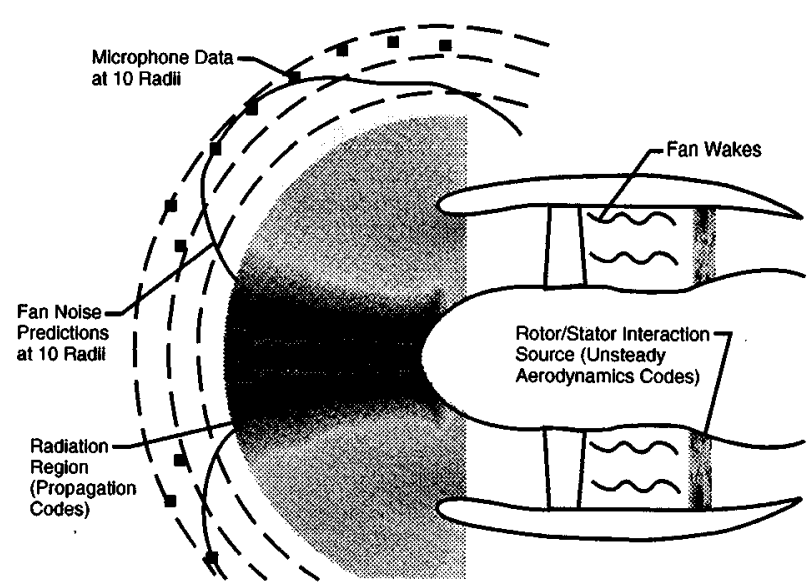

Figure 4. Measured and Predicted Fan Noise.

Nacelle Aeroacoustics-The goal of this research is to provide technology to increase the effectiveness of the nacelle in absorbing, canceling or redirecting turbomachinery noise. Research will include analytical modeling to estimate nacelle geometry effects on noise propagation; laboratory experiments to improve duct noise control treatments including passive, adaptive and active control strategies, and scaling validation of noise control technologies through scale model and full scale tests. The ultimate goal is to achieve a 50 percent increase in suppression effectiveness by the year 2000. An intermediate goal is to increase treatment efficiency by 25 percent by 1997. Figure 5 shows how existing high bypass ratio engines and long nacelle technology with passive acoustic 
acoustic treatment was feasible and effective. The program also enabled one to determine the weight and cost penalties associated with varying degrees of noise reduction by acoustic treatment.

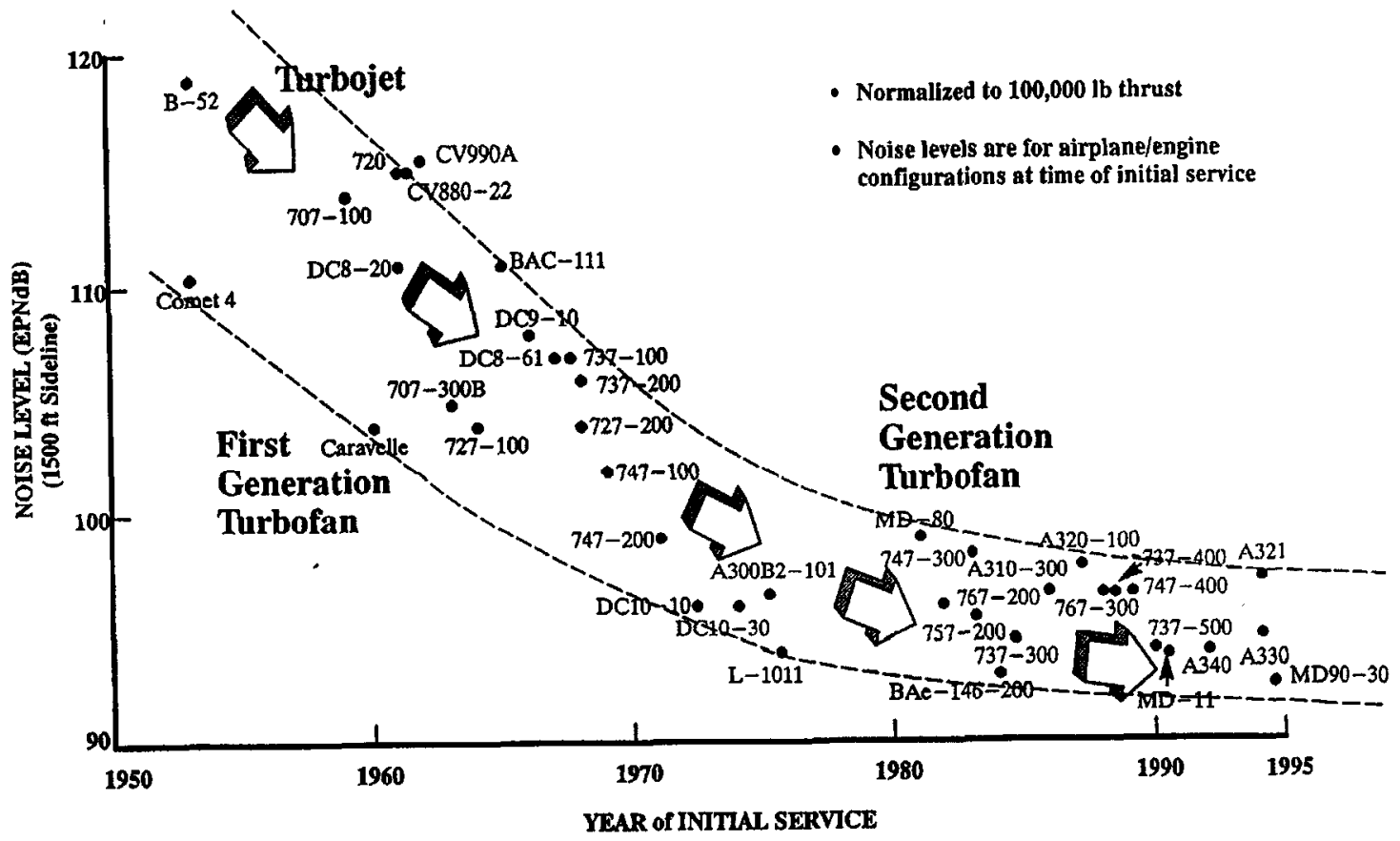

Figure 1. Progress in Noise Reduction.

During this 70's, research continued on a variety of techniques for reducing fan noise in the engine itself. These measures included eliminating inlet guide vanes, reducing the number of fan blade rows, reducing the rotational speed, increasing rotor/stator separation, and improving fan blade aerodynamic design. In the early 1970 's, these concepts were integrated and evaluated in ground tests of an experimental engine. The results of this Quiet Engine Program ${ }^{4}$ verified the predictions of considerable noise reduction in both approach and takeoff, and provided an improved data base for future designs.

In more recent NASA research programs, such as the Quiet, Clean, Short-Haul Experimental Engine $\left(\right.$ QCSEE $^{5}{ }^{5}$ program; the Quiet, Clean General Aviation Turbofan (QCGAT) ${ }^{6}$ program; and the Advanced Turboprop Program (ATP) ${ }^{7}$; noise reduction principles were extended to produce even quieter engines.

\section{ADVANCED SUBSONIC TECHNOLOGY NOISE REDUCTION PROGRAM.}

AST Program. In an effort to augment and accelerate ongoing subsonic technology in several key areas, NASA initiated the Advanced Subsonic Technology (AST) Program in late 1993. The goal of the AST program is to develop high payoff technologies to enable a safe, highly productive global air transportation system that includes a new generation of environmentally compatible, economical U.S. subsonic aircraft. The elements of the program are noise reduction, propulsion, integrated wing design, terminal area productivity, general aviation/commuter, civil tiltrotor, composites, aging aircraft, fly-by-light/power-by-wire, technology integration, and environmental assessment. The goal of the noise reduction program is to provide noise reduction technology readiness to achieve unrestrained market growth, increased U.S. market share, and compliance with international environmental requirements. To achieve this goal, NASA has established an objective of $10 \mathrm{~dB}$ noise reduction relative to 1992 technology. The objective will be achieved by combined noise reduction improvements in the engine, the aircraft system, and in aircraft operations

The AST noise reduction program and several other AST program elements are strongly related. Noise reduction is an enabling technology for the rotor and the design for the Civil Tiltrotor and will be a primary consideration in the development of its terminal area operating procedures. Noise reduction is also of prime importance to the general aviation/commuter element, the propulsion element, terminal area productivity and integrated wing elements of the program. The noise reduction element of the AST Program consists of five subelements depicted in Figure 2 namely, engine noise reduction, nacelle aeroacoustics, engine airframe integration, interior noise reduction, and airport community noise impact. Each of the subelements is discussed below. 